\title{
UN REFUGIO TAN PRECISO COMO INTERESANTE A LA REPÚBLICA: EL HOSPITAL DE LA CARIDAD DE CORUÑA, 1796-1805
}

\author{
Por \\ EVA SAMPAYO SEOANE
}

\section{OBJETIVOS Y PRESENTACIÓN DE LA FUENTE}

Nuestra intención al comenzar este breve trabajo era la de intentar demostrar la posible situación de la ciudad de la Coruña como polo de atracción de la población del entorno que la rodea, en un momento determinado ${ }^{1}$. El período elegido fue el tránsito del siglo XVIII al siglo XIX, concretamente el decenio de 1796-1805. Las razones de la elección de este lapso de tiempo fueron sobre todo la imposibilidad de usar esta fuente concreta para un período anterior, puesto que el primer registro de la serie comenzaba a mediados del año 1795.

La documentación consultada para la elaboración de este trabajo ha sido el registro de enfermos del Hospital de La Caridad de La Coruña. La elección de esta fuente posiblemente condicione el estudio de partida, ya que como todos sabemos, cualquier intento de acercarnos al fenómeno migratorio a través de una sola fuente ${ }^{2}$, ofrece una visión incompleta y

\footnotetext{
${ }^{1}$ Era nuestro deseo empezar el estudio de este fenómeno en un momento más temprano pero la inexistencia de las fuentes con las que hemos trabajado, para esa determinada época, nos ha hecho desistir de nuestro empeño en esta ocasión.

${ }^{2} \mathrm{Y}$ además de tipo indirecto, como casi todas las fuentes que existen para estudiar este fenómeno.
}

"CUADERNOS DE ESTUDIOS GALLEGOS", Tomo XLVI, Fascículo 111, Santiago 1999. 
bastante parcial de la realidad. Como en casi todas las fuentes hospitalarias, en este caso nos encontramos con que solo aparece reflejado un sector muy particular de la población, en concreto las clases más humildes y desfavorecidas de la sociedad (al menos en teoría, pues habrá excepciones, como luego veremos). Esto motivará que en algunos casos, por ejemplo a la hora de evaluar a la población, nos aparezca un elevado número de personas procedentes de fuera de la ciudad, algo lógico, puesto que al tratarse de un hospital para indigentes, en él se da cabida a aquéllos que acuden a la Coruña, especialmente a los que carecen de recursos.

Para familiarizarnos un poco con la fuente, recordaremos brevemente la historia de este «Hospital de la Caridad», que fue fundado en 1794 con los bienes que Teresa Margarita Herrera dejó a la Congregación del Divino Espíritu Santo y María Santísima de los Dolores, para ayudar y recoger a los pobres. Al Hospital se le añadía además un Hospicio o Casa de Misericordia, y una inclusa, pues la situación asistencial en la ciudad durante este período debía de ser bastante caótica. Así lo deja ver el siguiente informe de la Junta de Gobierno del Hospital, para determinar sus estatutos y atribuciones:

«-.... recolección de una multitud de los que inundan las calles y entradas de las casas, formando entre si una república libre, abandonada y viciosa, para dedicarlos a las labores en que pueda emplearseles y sacar los cuartos de su alimento .....

- ... igual recogimiento de un considerable número de mugeres publicas y poco fieles [...] sabiendo que no ai donde encerrarlas para su continencia [...], andan como bagantes de unos pueblos en otros, contagiando con sus torpes tratos y comunicaziones a quantos las ben, de que son testigos los hospitales en que no caben los que necesitan curarse de mal galico .....

- ... socorro de los muchos niños expósitos ....

- ... lograremos desde luego vaxo la voluntad del Altísimo ver en pocos años un hospital, una casa de expósitos y un hospizio para estos naturales y sus provincianos» ${ }^{3}$.

\footnotetext{
${ }^{3}$ Archivo Municipal de La Coruña (A.M.C.), Junta Municipal de Beneficencia, caja $\mathrm{n}^{\circ} 79$.
}

"CUADERNOS DE ESTUDIOS GALLEGOS", Tomo XLVI, Fascículo 111, Santiago 1999. 
Puede verse, desde luego, en este elocuente texto de la Junta de Gobierno del Hospital parte de ese espíritu ilustrado, tan característico de finales del siglo XVIII preocupado por eliminar la mendicidad y el despilfarro de los ciudadanos útiles para la nación ${ }^{4}$.

En un Memorial de la Congregación de el Espíritu Santo y María Santísima de los Dolores y la Junta de Gobierno del Hospital de la Caridad, en Junio del año 1795 se añade:

«... se recogieron y asisten hasta 76 pobres de ambos sexos y edades, ynclusos lo jovenes guerfanos y abandonados que a todas horas, de dia y de noche se veian gimiendo por las calles, careciendo hasta del socorro espiritual ....»

"Jamas hubo en este pueblo cuia remota fundación se ignora, un refugio tan preciso como interesante a la Republica, y de que todas las naciones cultas han ciudado ...»

"... se veian hasta aora arrojadas estas desdichadas criaturas en las calles, en los atrios de las Yglesias, encima de sus altares, y hasta en las pilas de agua bendita, en los portales de las casas, en las riberas de la Marina, entre los fosos de la Fortificacion, en los muladares y en otros sitios. No pocas veces gimio la humanidad, y se estremecieron los menos sensibles al hallar los fragmentos de aquellos cuerpecitos que habían dejado la voracidad de los perros, y al hallar arrojados otros por las olas del mar, con evidente demostración de que habian sido echados en el mar por unas madres fieras, desnaturalizadas, o por efectos de una venganza que las precipita en la desesperación,

${ }^{4}$ Incluso unos cuantos años más adelante -en 1798- se creará dentro del propio Hospital una escuela de hilanderas: «... concurren los jovenes a la Escuela Real, y a las niñas se las enseña a trabajar con la ahuja, viendose limpios en lugar de la miseria en que estaban constituidos y serian unas personas inutiles ...»; A.M.C. Libros de Actas, Caja n $^{\circ}$ 80, f. 275 (30-VI-1795). Pero no será este un caso excepcional dentro del panorama asistencial español. Son numerosos los ejemplos de creación de instituciones similares -incluso anteriores- al socaire de dicho espíritu. PALOMARES IBÁÑEZ, J. M ${ }^{\mathrm{a}}$.: «El arzobispo Rajoy y los orígenes del Hospicio de Pobres de Santiago». Compostellanum, (1977). Págs 235-359; CARASA SOTO, P. Pauperismo y revolucion burguesa (Burgos, 1750-1900). Valladolid, 1987. Págs 456 y ss.; MAZA ZORRILLA, E.: Valladolid: sus pobres y la respuesta institucional (1750-1900). Valladolid, 1985. Págs 50 y ss.

"CUADERNOS DE ESTUDIOS GALLEGOS", Tomo XLVI, Fascículo 111, Santiago 1999. 
por encubrir su flaqueza, o por exceso de corrupcion de costrumbres e ideas de disolucion inhumana ...»

".... en que se han recivido y curado muchas pobres enfermas y proximas a parir y otras a restablecerse ....».

También en estos textos se puede apreciar claramente el tipo de «clientela» que nos encontraremos formando parte de la población de la ciudad y que en alguna ocasión durante este período (1796-1805) acaba dando con sus huesos en una de las escasas camas del Hospital.

Como antes mencionábamos, la fuente utilizada ha sido el registro de entrada de enfermos del Hospital. En él anotaba un párroco -en esta ocasión, pues en ã̃os venideros anotará los datos un celador del mismo Hospital- los siguientes datos: nombre y apellidos del enfermo, edad, estado civil, lugar de nacimiento, y tan solo en ocasiones su profesión y la enfermedad por la que había ingresado en el Hospital de la Caridad.

En nuestro caso concreto hemos optado por un vaciado nominal sistemático - para evitar en la medida de lo posible las repeticiones ${ }^{6}$ que desvirtuarían los porcentajes- de las personas internadas en el centro durante el decenio de 1796-1805, lo que supone casi un total de 1300 individuos. Desgraciadamente es muy difícil encontrar un registro en el que aparezcan recogidos todos los datos anteriores, pues en ocasiones faltan la edad, en otras el estado civil, otras veces faltan los días de estancia, en otras ocasiones -las menos- el sacerdote se olvida de anotar el lugar de donde es natural, .... .

¿Y cuáles son los problemas que presenta en concreto, el registro de enfermos del Hospital como fuente para estudiar la población de la Coruña? Pues son muy variados y algunos de ellos ya han sido esbozados con anterioridad. Uno podría ser que tiende a primar más a la población foránea, pues es la que menos recursos tiene a la hora de costear y buscar un «médico de confianza», dada su condición de re-

\footnotetext{
${ }^{5}$ A.M.C., Libros de Actas, Caja no 80, f. 274-275.

${ }^{6}$ Además estas personas repetidas pueden constituir un indicador de la presencia más o menos continua de un individuo en la ciudad, puesto que si esa persona es forastera y aparece en más de una ocasión en el hospital, podemos suponer que reside en la Coruña, y más cuando estas menciones se suceden a lo largo de los años.
} 
cién llegado a la localidad, y por consiguiente, ésta es la que aparece mayoritariamente en los registros.

A través de estas series solo podemos acceder a un grupo muy reducido de población, el sector más humilde, con lo que no podremos tener una visión completa de toda la sociedad, sino solo de un sector muy específico. Hay algunos sectores de la población que aparecen también sobredimensionados en los datos que ofrece la fuente, y suponemos que podría ser por el hecho de contar con una inclusa y un hospicio, lo que podría «inflar» un tanto las cifras. Pero no sólo por esta razón pueden aparecer elevados porcentajes en algún tramo de edad -sobre todo en los tramos extremos- ya que hay que tener un cuenta que a un hospital acude gente enferma, y los sectores de población que, en buena lógica, eran más proclives a padecer cualquier tipo de enfermedad -al menos en teoríaserían la población infantil y la de mayor edad, y por lo tanto más débil, con lo que pueden aparecer en mayor medida que el resto de la población.

Lógicamente tampoco recoge a toda la población de una localidad que se pueda haber trasladado a la ciudad, puesto que no todo el mundo tiene por que verse en la obligación de pasar por el hospital, con lo que siempre se nos escapará un porcentaje de los moradores de la Coruña, que será difícil de evaluar.

Después de haber visto las particularidades de la fuente, nos queda por decir que los resultados que hemos extraído de los registros que tenemos, y que comentaremos a continuación, no dejan de ser unos meros indicadores, de lo que ocurría en la ciudad, y que sólo podremos aproximarnos a las características de la población foránea, pero de un modo muy indirecto, y siempre con cifras aproximadas, que nunca pretenden tener un valor absoluto, y sí validez como indicadores de una tendencia.

\section{LA POBLACIÓN. PROCEDENCIA Y DISTRIBUCIÓN}

Como podemos ver en la Tabla I, la gran mayoría de la población que pasa por el hospital en este período de tiempo es de fuera de la Coruña. Tanto en el caso de los hombres como en el de las mujeres una pequeña minoría -en ningún caso se supera el $25 \%$ - son naturales de la propia ciudad, y el resto ha llegado de fuera. Ya hemos podido ver antes como posiblemente este gran desajuste entre la población autóctona y la foránea 
venga motivado por la fuente utilizada, puesto que lo lógico sería que la población autóctona fuese la dominante como sucede en otras ciudades gallegas en el mismo período ${ }^{7}$.

Tabla I. Población que pasa por el Hospital de la Caridad, 1796-1805

\begin{tabular}{cccc|cccc}
\hline \multicolumn{3}{c|}{} & \multicolumn{4}{c}{ HOMBRES } \\
\hline \multicolumn{2}{c|}{ AUTÓCTONAS } & \multicolumn{2}{c|}{ FORASTERAS } & \multicolumn{2}{c}{ AUTÓCTONOS } & \multicolumn{2}{c}{ FORASTEROS } \\
\hline 178 & $24,80 \%$ & 540 & $75,20 \%$ & 96 & $20,12 \%$ & 381 & $79,87 \%$ \\
\hline
\end{tabular}

$\mathrm{Y}$ estos forasteros ¿cómo se reparten en cuanto a su procedencia? Si observamos la Tabla II, podremos hacernos una idea de cuales eran sus lugares de origen.

Tabla II

\begin{tabular}{lrrrrrr}
\hline Procedencia & \multicolumn{2}{c}{ Mujeres } & \multicolumn{2}{c}{ Hombres } & \multicolumn{2}{c}{ Total } \\
\hline Gallegos & 435 & $47,23 \%$ & 232 & $25,19 \%$ & 667 & $72,42 \%$ \\
Resto de España & 102 & $11,07 \%$ & 89 & $9,66 \%$ & 191 & $20,73 \%$ \\
Extranjero & 2 & $0,21 \%$ & 42 & $4,56 \%$ & 44 & $4,77 \%$ \\
América Hispana & 1 & $0,10 \%$ & 18 & $1,95 \%$ & 19 & $2,06 \%$ \\
Totales & 540 & $58,63 \%$ & 381 & $41,36 \%$ & 921 & $100 \%$ \\
\hline
\end{tabular}

En el cuadro anterior hemos visto el predominio de la procedencia gallega en los orígenes de los que en su día pasaron por el hospital. A continuación veremos en que medida influye la distancia en los desplazamientos de estas personas. Para abordar la cuestión gallega hemos trazado unos radios, en torno a la ciudad de la Coruña, de diez en diez kilómetros. Los resultados que hemos obtenido han sido los siguientes (Tabla III):

${ }^{7}$ MARTÍNEZ RODRÍGUEZ, E., BURGO LÓPEZ,C., GONZÁLEZ LOPO, D.: «Inmigración urbana en la Galicia del A.R.: Santiago, Tuy y Ferrol a finales del siglo XVIII» en Actas de la I Conferencia Europea de la Comisión Internacional de Demografía Histórica. Santiago, 1993. El caso de Ferrol es un caso excepcional dentro del panorama urbano gallego.

"CUADERNOS DE ESTUDIOS GALLEGOS", Tomo XLVI, Fascículo 111, Santiago 1999. 
Tabla III

\begin{tabular}{rrrrrr|r|rrrrrr}
\hline \multicolumn{10}{c}{ MUJERES } \\
\hline $\mathrm{S}$ & $\mathrm{C}$ & $\mathrm{V}$ & $\mathrm{SE}$ & $\%$ & $\mathrm{~T}$ & $\mathrm{KM}$ & $\mathrm{T}$ & $\%$ & $\mathrm{SE}$ & $\mathrm{V}$ & $\mathrm{C}$ & $\mathrm{S}$ \\
\hline 12 & 11 & 9 & 3 & 8,88 & 35 & $0-10$ & 46 & 19,82 & 5 & 3 & 25 & 13 \\
63 & 29 & 18 & 8 & 29,94 & 118 & $10-20$ & 54 & 23,27 & 5 & 8 & 20 & 21 \\
16 & 2 & 9 & 2 & 7,36 & 29 & $20-30$ & 22 & 9,48 & 3 & 3 & 6 & 10 \\
22 & 10 & 6 & 4 & 10,65 & 42 & $30-40$ & 17 & 7,32 & 4 & 1 & 6 & 6 \\
10 & 4 & 5 & 1 & 5,07 & 20 & $40-50$ & 6 & 2,58 & - & - & 2 & 4 \\
21 & 13 & 12 & 2 & 12,18 & 48 & $50-60$ & 27 & 11,63 & 2 & 2 & 13 & 10 \\
5 & 8 & 2 & 2 & 4,31 & 17 & $60-70$ & 5 & 2,15 & 1 & - & 1 & 3 \\
15 & 5 & 6 & - & 6,60 & 26 & $70-80$ & 13 & 5,60 & 2 & 1 & 6 & 4 \\
13 & 8 & 3 & - & 6,09 & 24 & $80-90$ & 20 & 8,62 & - & 1 & 15 & 4 \\
3 & 2 & 2 & 1 & 2,03 & 8 & $90-100$ & 5 & 2,15 & - & - & 1 & 4 \\
7 & 1 & 1 & 4 & 3,30 & 13 & $100-110$ & 2 & 0,86 & - & - & - & 2 \\
4 & 2 & 4 & - & 2,53 & 10 & $110-120$ & 10 & 4,31 & 2 & 1 & 1 & 6 \\
- & - & - & - & - & - & $120-130$ & 2 & 0,86 & - & 1 & 1 & - \\
- & 2 & - & 1 & 0,76 & 3 & $130-140$ & - & - & - & - & - & - \\
1 & - & - & - & 0,25 & 1 & $140-150$ & - & - & - & - & - & - \\
- & - & - & - & - & - & +150 & 3 & 1,29 & 1 & - & 1 & 1 \\
\hline 192 & 97 & 77 & 28 & 8 & 394 & TOTALES & 232 & & 25 & 21 & 98 & 88 \\
\hline
\end{tabular}

$\mathrm{S}=$ Solteros/as; $\mathrm{C}=$ Casadas/os; $\mathrm{V}=$ Viudas/o $;$ S.E. $=$ Sin especificar $; \mathrm{T}=$ Totales

Como sucede en otras ocasiones, la proximidad resulta ser la clave para explicar la mayor parte de los movimientos migratorios, que tienen como destino en esta ocasión la ciudad de la Coruña. De los alrededores de la ciudad, en torno a un radio máximo de unos 50 kilómetros, proviene la mayoría de la población (alrededor de un $74 \%$ del total) tanto en el caso de los varones como en el de las mujeres.

${ }^{8}$ Esta diferencia de mujeres que hay con respecto al número de gallegas que aparecen en el cuadro anterior es debida a que son aproximadamente unas 40 féminas que sabemos que son gallegas, pero nos ha sido imposible identificar su lugar de origen, en unas ocasiones porque no lo especificaba el párroco encargado de anotarlas ( ... natural del obispado de Mondoñedo», «... de la provincia de Orense», etc.) y otras veces porque nos resultó imposible identificar el lugar o feligresía que se mencionaba.

"CUADERNOS DE ESTUDIOS GALLEGOS", Tomo XLVI, Fascículo 111, Santiago 1999. 
A medida que la distancia se va haciendo mayor va disminuyendo el número de personas que aparecen registradas en el Hospital ${ }^{9}$.

A la vista de estos datos, es de las comarcas periféricas de donde provienen la mayor parte de los individuos gallegos que podemos encontrar durante este período en la Coruña. En lo referente a las mujeres estas suelen ser en una gran proporción mozas solteras (un 48,73\%), seguidas a distancia por un notable contingente de féminas casadas $(24,61 \%)$ y de mujeres viudas $(19,54 \%)$ y por último una proporción de mujeres en las que el párroco encargado de anotarlas en el registro no puede precisar su estado civil $(7,10 \%)$. Este comportamiento de la población femenina podría considerarse como normal y similar a lo que sucede en otras ciudades de la época ${ }^{10}$.

La población masculina presenta unas pautas de comportamiento similares a las de las féminas con respecto a su radio de acción, pero difiere un tanto de éstas en lo que se refiere al estado civil de los que se encuentran en la ciudad. En esta ocasión el predominio es de los casados $(42,24 \%)$, frente a los célibes (un 37,93\% del total) y los viudos $(9,05 \%)$, y los varones inclasificados $(10,77 \%)$. Como podemos observar el porcentaje de mujeres viudas dobla al de individuos varones en el mismo estado. Y ¿cómo podríamos explicar esta situación, esta mayor presencia de mujeres viudas en la ciudad? Pues posiblemente una de las razones pudiera ser la mayor indefensión económica de las mujeres, la imposibilidad de salir adelante, ante la muerte del cónyuge, lo que las obligaría a buscar refugio en la ciudad, donde o bien podrían trabajar -cuando se trata de viudas jóvenes o relativamente jóvenes- o podrían tratar de buscar una solución a su situación en un lugar como por ejemplo pudiera ser un hospicio como en el caso que nos ocupa.

Destaca también en esta tabla la disminución de los porcentajes conforme la distancia se va haciendo mayor, salvo pequeñas excepciones,

${ }^{9}$ Como sucede en otras ciudades con hospitales similares. Véase MAZA ZORRILLA, E.: Valladolid: sus pobres y la respuesta institucional (1750-1900). Valladolid, 1985. Pág 151 y ss.; CARASA SOTO, P.: Pauperismo y revolucion burguesa (Burgos, 1750 1900). Valladolid, 1987. Pág. 236 y ss.

${ }^{10}$ FAUVE-CHAMOUX, A., «Female mobility and urban population in preindustrial France (1500-1900)», en Actas de la I Conferencia Europea de la Comisión Internacional de Demografia Histórica. Santiago, 1993, Pág 43-72.

"CUADERNOS DE ESTUDIOS GALLEGOS", Tomo XLVI, Fascículo 111, Santiago 1999. 
que se producen cuando nos encontramos con un núcleo de población de cierta entidad ${ }^{11}$. Si nos detenemos brevemente en la tabla veremos que en la franja de 30-40 kilómetros, donde hemos incluido a Ferrol ${ }^{12}$, se rompe esta tendencia de disminución de porcentajes. Parece ser Ferrol una ciudad emisora de población femenina ${ }^{13}$, por lo general soltera, y bastante joven, pues de las 42 mujeres que tenemos registradas en ese tramo, 17 dicen ser naturales de Ferrol, por tan solo 5 varones (de los 17 totales) que declaran ser de esta villa.

A continuación un notable ascenso, en el tramo de 50-60 kilómetros, al encontrarnos en él con la ciudad de Santiago. Son 29 referencias de mujeres y 15 de hombres que se distribuyen como sigue: 12 solteras, 5 casadas, 10 viudas, 2 mujeres sin determinar, 5 solteros, 8 casados, un viudo y una persona de la que no se especifica su estado civil. Sorprende en este caso el elevado número de viudas que, procedentes de la ciudad de Santiago, recalaban en el hospital de la Coruña.

El siguiente tramo que vuelve a aumentar ligeramente los porcentajes con respecto al anterior es el de 70-80 kilómetros, en el que se encuentra comprendida la ciudad de Lugo. Como podemos observar, nuevamente se incrementan los porcentajes, sobre todo en el caso de las mujeres, que son en su mayoría solteras.

Ya a partir de aquí la cifra de personas que desde estas distancias acuden a la Coruña va disminuyendo considerablemente, puesto que no hay que olvidar que ya hemos salido de la actual provincia de la Coruña, que es la que en buena medida provee de habitantes a su capital. Pero aún así hay tramos que vuelven a llamar nuestra atención. Uno de ellos es, por ejemplo, el de 80-90 Kms, que en el caso de los hombres presenta un porcentaje relativamente alto. Pero más que su número lo que nos

\footnotetext{
${ }^{11}$ Con lo que lógicamente, además de la distancia, también influye la densidad de población de la zona.

${ }^{12}$ Hemos incluido a Ferrol en este tramo, pues si bien es cierto que Ferrol en línea recta tendríamos que incluirlo en el tramo de 10-20 kilómetros, no es menos cierto que la distancia real que separa Ferrol de la Coruña supera ampliamente esos 10-20 kilómetros, con lo que hemos optado por abarcarla con el tramo de 30-40 kilómetros, para tratar de aproximarnos más a la situación real.

${ }^{13}$ Aunque esto pudiera deberse a la sobrerrepresentación de la población femenina en la fuente utilizada.
}

"CUADERNOS DE ESTUDIOS GALLEGOS", Tomo XLVI, Fascículo 111, Santiago 1999. 
ha llamado la atención en este caso es su homogeneidad. En efecto, de un total de 12 individuos repartidos por distintas parroquias de Moraña -sobre todo- y Campo Lameiro -en menor número-, 11 están casados, y solo uno de ellos permanece soltero. Además, en todas estas localidades solo hay referencia a una única mujer.

Ya en los últimos tramos, a partir de los 100 kilómetros, únicamente hay que destacar una particularidad. Consiste ésta, en que las mujeres que encontramos a partir de esta distancia proceden en su mayoría de la provincia de Pontevedra ${ }^{14} \mathrm{y}$, por el contrario la casi totalidad de la población masculina, llega a Coruña procedente de la provincia orensana ${ }^{15}$.

Otra característica de la población gallega que encontramos durante 1796-1805 en Coruña, es que la mayoría suele proceder de las zonas más occidentales. Así, cuanto más avanzamos hacia el este, y nos adentramos en las provincias de Lugo y Orense -y no sólo al salir de la provincia, sino al penetrar en el sector más oriental de la provincia de la Coruña: Sobrado, Curtis, Vilasantar, Aranga, Monfero, Boimorto, ....- decae considerablemente el número de personas que provienen de estas zonas ${ }^{16}$. Además, en la parte occidental más alejada de la ciudad, normalmente las menciones suelen provenir de zonas costeras, por ejemplo Muxia, Laxe, Camariñas, Moraime, Corcubión, ... y a partir de ahí nos encontramos con referencias a lugares situados en torno al litoral atlántico: Muros, Noya, Outes, Negreira, Puebla, Rianxo, Vigo, Baiona, ..., sin adentrarnos apenas en el interior de la provincia de Pontevedra.

Por lo que respecta a sus edades, como podemos ver en el Tabla IV, la mayor parte de esta población que no son naturales de la Coruña, tiene entre 16-40 años ${ }^{17}$. Son personas, sobre todo las mujeres, bastante jóvenes que vienen por lo general, de las comarcas limítrofes con la Coruña.

\footnotetext{
${ }^{14}$ En su mayoría de su parte más Occidental como por ejemplo, Moaña, Vigo, Bayona, Tuy, ..., aunque siempre hay excepciones que nos remiten a la zona interior de la actual provincia de Pontevedra.

${ }^{15}$ En concreto de su capital, Orense, y de comarcas más alejadas como Gomesende, Xinzo de Limia, Monterrey, Viana do Bolo, Carballeda, .... .

${ }^{16}$ Probablemente, los individuos de estas zonas tienen otros puntos de destino más atrayentes que la propia ciudad de la Coruña: Santiago, Lugo, ... .

${ }^{17}$ El $72,4 \%$ en el caso de las mujeres y el $52,5 \%$ en el de los hombres.
}

"CUADERNOS DE ESTUDIOS GALLEGOS", Tomo XLVI, Fascículo 111, Santiago 1999. 
Por lo que se refiere a los hombres, estos doblan a las mujeres en el tramo de edad que va desde 41-55 años. ¿La explicación? Esta situación podría estar relacionada con las actividades laborales que esa persona desarrollara en la ciudad. Se trata, como veremos durante el trabajo, de gente en su mayoría sin especializar, y la ciudad posiblemente demande mano de obra joven, barata y femenina -en su mayoría- en este momento, con lo que su presencia a partir de una cierta edad ya no sería tan solicitada, y tal vez esto pudiera explicar esta desigual situación. Quizá también esta población femenina al llegar a una etapa concreta de su vida pueda plantearse el regresar a su lugar de origen. Sea por la razón que fuere, lo cierto es que hay una mayor presencia de hombres maduros que vienen de fuera en la ciudad que de mujeres en la misma situación.

El tramo inferior 0-15, no parece estar muy influido por el hecho de contar el Hospital con una inclusa, y de hecho, no está muy representado dentro de la población foránea, y si mucho más dentro de la población natural de la propia ciudad ${ }^{18}$.

Tabla IV. Distribución por tramos de edad de la población foránea

\begin{tabular}{ccrcrr}
\hline EDADES & MUJERES & $\%$ & HOMBRES & $\%$ & TOTALES \\
\hline $0-15$ & 16 & 3,07 & 35 & 8,75 & 51 \\
$16-25$ & 188 & 36,15 & 106 & 26,5 & 294 \\
$26-40$ & 187 & 35,96 & 104 & 26 & 291 \\
$41-55$ & 49 & 9,42 & 77 & 19,25 & 126 \\
+55 & 80 & 15,30 & 78 & 19,5 & 158 \\
\hline TOTALES & 520 & 100 & 400 & 100 & 920 \\
\hline
\end{tabular}

Como también hemos comentado antes, posiblemente pueda ser la fuente la que nos ayude a explicar este aumento de personas en el último tramo de edad. Sin embargo, como hemos apuntado en el caso de las viudas, este elevado porcentaje de personas ya mayores, podría ser debido a que buscaban en la ciudad de la Coruña una «seguridad» que sus

${ }^{18}$ De la que supone casi un $17,61 \%$ de la población autóctona.

"CUADERNOS DE ESTUDIOS GALLEGOS", Tomo XLVI, Fascículo 111, Santiago 1999. 
lugares de origen no podrían ofrecerles, y se aventuraban a venir hasta la ciudad en busca de unos recursos que en el campo les resultaban imposibles de encontrar ${ }^{19}$.

Llegados a este punto, podríamos preguntarnos ¿ y cuál podría ser la razón por la que la ciudad de la Coruña actuaba como foco de recepción de todos estos individuos, procedentes de las comarcas limitrofes con la ciudad en su mayoría? Las razones podrían ser muy diversas, y por supuesto, lo único que podemos hacer es aventurar algunas posibles causas, pero sin descartar ni afirmar categóricamente ninguna. Una posible hipótesis que se nos ocurre, es que en este momento concreto, la ciudad de La Coruña ofrece unas perspectivas laborales nada desdeñables. Podría considerarse como una localidad dinámica, pujante y con un notable centro manufacturero. Si nos detenemos un poco en estos pasajes de J. Lucas Labrada podremos observarlo con más detalle:

«La principal industria de esta ciudad es la de las lencerías, pues además de la Real Maestranza de Mantelería [...] hay también esparcidos por la población y sus arrabales como unos ciento y trece telares de lienzos [...] veinticinco o treinta de ellos trabajan todo el año, los demás solo lo hacen uno o dos meses. Una fábrica de sombreros finos [...] ocupándose en ella, en el día, de 135 a 140 operarios de ambos sexos además de unos 40 aprendices. [...] Hay además de ésta, otra pequeña fábrica de sombreros finos y tres de ordinarios [...]. Asimismo existe en esta ciudad una considerable fábrica de jarcia y cordeleria [...]. Hay también una de pasamaneria y cintas y dos de peines.»

"En efecto, este puerto ha sido siempre uno de los más frecuentados del reino, por dar franca entrada a todos los buques que navegan por esta costa [...] hasta el año 1778 en que se expidió el Reglamento

\footnotetext{
${ }^{19}$ Esta presencia numerosa de mujeres que viven solas en las ciudades, solteras y viudas, ha sido puesto de manifiesto en varios trabajos. Véase CHAUNU, P.: La mort à Paris. XVIe, XVIIe, XVIIIe siécles. Paris, 1978, pág. 193. FAUVE- CHAMOUX, A.: «Innovation et compportament parental en milieu urbain (XVe-XIXe siécles)». Annales (1985), pág. 1024.
} 
del Libre Comercio [...], no puede decirse que este puerto fuese una verdadera plaza de comercio» ${ }^{20}$.

Como vemos, la ciudad poseía, para la época una incipiente «industria ${ }^{21} \gg$ y un no menos desarrollado comercio, sobre todo tras la instalación de los Correos Marítimos con Ultramar en 1764 y el Decreto de Libre comercio con América en $1778^{22}$, que «... hace que para las introducciones de los extranjeros y de los efectos coloniales no se ha limitado solo a su consumo, sino al de algunos pueblos de Castilla y Galicia, que caen más cerca de este que de aquel puerto (el de Ferrol), y cuyos caminos se hallan en gran parte franqueados $»^{23}$ que convertiría a la capital en un lugar apetecible para la población de los alrededores.

Además no hay que olvidar que en su mayoría -como veremos más adelante- son personas procedentes del campo, mano de obra sin cualificar y no especializada por tanto, y en este momento estamos en una fase de «degradación y pauperización del mundo rural» tras las cosechas deficitarias de $1788-1789^{24}$. De ahí que no sería de extrañar que el excedente de población de las comarcas cercanas a la Coruña, optara por acercarse a la ciudad para conseguir salir adelante. Y la misma causa podemos aplicar para las personas que no procedan de las proximidades de la Coruña: las posibilidades de mejora ante una situación de degradación general, aproximándose a un lugar en fase de despegue económico.

${ }^{20}$ LUCAS LABRADA, J., Descripción económica del Reino de Galicia, Vigo, 1971, págs 41 y ss.

${ }^{21} \mathrm{~A}$ las anteriores industrias citadas, hay que unir desde 1804 (coincidiendo además con un fuerte incremento en el número de féminas, que llegan al Hospital) -y de forma oficial desde 1808- la Fábrica de Tabacos que da trabajo a un considerable número de mujeres.

${ }^{22}$ Para este tema puede consultarse L. ALONSO ÁLVAREZ, Comercio Colonial y Crisis del Antiguo Régimen en Galicia (1778-1818), Sada, 1986.

${ }^{23}$ J. LUCAS LABRADA, Descripción Económica del Reino de Galicia; Vigo, 1971.

${ }^{24}$ Véase A. EIRAS ROEL, Estudios sobre agricultura y población en la España Moderna; Santiago, 1990, pp. 122 y ss.

"CUADERNOS DE ESTUDIOS GALLEGOS", Tomo XLVI, Fascículo 111, Santiago 1999. 


\section{EL «RESTO DE ESPAÑA»}

Por lo que se refiere a las áreas más alejadas, en lo que hemos denominado «Resto de España», observamos también una mayor presencia de mujeres frente a los hombres, aunque en este caso los porcentajes son más igualados que cuando nos referimos a los gallegos. Están representadas en esta muestra la casi totalidad de las regiones españolas, formando un grupo bastante heterogéneo en el que destacan de forma considerable los individuos de las regiones más próximas, predominando sobre todo los de la zona norte. Es en esta franja norte donde las mujeres aparecen más representadas, destacando sobretodo Asturias, Cantabria, el País Vasco, La Rioja y Navarra como las regiones que más féminas aportan y donde su porcentaje supera ampliamente -muy ampliamente en casi todos los casos- al de los hombres. Las otras zonas, que podríamos considerar como más alejadas, se caracterizan por una mayor movilidad de los hombres frente a la escasa presencia femenina en el total de estas regiones. Se confirma así el mayor radio de acción de los hombres -su mayor movilidadfrente una escasa presencia femenina conforme aumentan las distancias a recorrer.

Tomando como base los datos que tenemos, la inmigrante tipo de esta zona norte parece ser una mujer joven, concretamente entre 16 y 25 años de edad, soltera ${ }^{25}$, y en el caso concreto de las originarias de Asturias, pertenecientes a dos zonas determinadas, como son por un lado la comarca de Oviedo, Avilés y sus valles periféricos, y por otro, los valles de montaña de la Asturias Occidental, limítrofes con la montaña luguesa. Los demás individuos de la franja norte formarían una masa muy heterogénea con orígenes muy diversos, y con una mayor dispersión en cuanto a sus lugares de procedencia.

Su distribución sería la que podemos ver en la Tabla V:

${ }^{25}$ De un total de 28 menciones de mujeres, 15 de ellas son anotadas como solteras.

"CUADERNOS DE ESTUDIOS GALLEGOS", Tomo XLVI, Fascículo 111, Santiago 1999. 
Tabla V

\begin{tabular}{lrcc}
\hline REGIONES & TOTAL & MUJERES & HOMBRES \\
\hline Andalucía & 12 & 2 & 10 \\
Aragón & 9 & 6 & 3 \\
Asturias & 46 & 28 & 18 \\
Baleares & 1 & - & 1 \\
Canarias & 1 & 1 & - \\
Cantabria & 12 & 9 & 3 \\
Castilla la Mancha & 9 & 3 & 6 \\
Castilla - León & 28 & 14 & 14 \\
Cataluña & 10 & 4 & 6 \\
Extremadura & 2 & 1 & 1 \\
La Rioja & 3 & 3 & - \\
Madrid & 10 & 2 & 8 \\
Murcia & 4 & - & 4 \\
Navarra & 10 & 8 & 2 \\
País Vasco & 24 & 17 & 7 \\
Valencia & 10 & 4 & 6 \\
\hline TOTAL & 191 & 102 & 89 \\
\hline
\end{tabular}

Los individuos representantes de la zona meridional del país no demuestran un origen tan disperso como los de la zona norte y parecen mostrar una tendencia a proceder todos de unas cuantas ciudades muy concretas. Así, por ejemplo en el caso de Andalucía de un total de 12 menciones, 4 corresponden a Sevilla, 3 son de Cádiz, 3 de Granada, 1 persona es de Málaga, y mencionan en una ocasión a una persona de Andalucía pero sin especificar de donde; es decir, en su mayoría puertos comerciales cuyos contactos con el de Coruña explicarían su presencia en estas tierras del norte.

"CUADERNOS DE ESTUDIOS GALLEGOS", Tomo XLVI, Fascículo 111, Santiago 1999. 


\section{LOS EXTRANJEROS}

Una vez más la proximidad geográfica es la que explica -en parte- la mayor o menor presencia de extranjeros en nuestra ciudad. Así, podemos ver en la Tabla VI, como la mayor cantidad de extranjeros provienen del vecino Portugal.

Tabla VI

\begin{tabular}{lccc}
\hline PAISES & MUJERES & HOMBRES & TOTALES \\
\hline Portugal & - & 23 & 23 \\
Italia & - & 11 & 11 \\
Francia & 2 & 5 & 7 \\
Suecia & - & 1 & 1 \\
Luxemburgo & - & 1 & 1 \\
Países Bajos & - & 1 & 1 \\
\hline TOTAL & 2 & 42 & 44 \\
\hline
\end{tabular}

De estos 23 individuos que proceden de Portugal, la inmensa mayoría dicen ser naturales de las inmediaciones de Oporto (o por lo menos pertenecientes a su obispado ${ }^{26}$ ). Solo hay dos personajes que llegan a la Coruña desde Lisboa -capital- uno, y el otro de un lugar situado a unas cuantas leguas de la ciudad lisboeta, como es Santarém (también ciudades portuarias).

Del resto poco se puede decir salvo que su presencia resulta meramente testimonial, exceptuando a los que vienen de Francia y sobre todo de Italia. Podría sorprender la nula presencia de ingleses, por lo menos reflejados en este hospital, en este momento, ya que no debemos de olvidar que las relaciones comerciales con Inglaterra desde el puerto de la Coru-

${ }^{26}$ Un tal Jose de Castro de 50 años, operario de una fábrica de sombreros, dice ser natural de Santa María de Vilanova de Gaia (obispado de Oporto), donde residen sus padres y su mujer. Y otros cuatro que ingresan juntos el mismo día -entre 18-28 añosque declaran ser de Oporto, donde viven sus padres.

"CUADERNOS DE ESTUDIOS GALLEGOS", Tomo XLVI, Fascículo 111, Santiago 1999. 
ña se remontaban a unos cuantos siglos atrás ${ }^{27}$, aunque tampoco es menos cierto que en esta fase final de siglo XVIII las acciones bélicas que enfrentaban a España e Inglaterra eran bastante frecuentes, y de hecho en 1800 la ciudad estuvo amenazada por un desembarco inglés, después de un intento fallido en Ferrol ${ }^{28}$.

\section{LA AMÉRICA ESPAÑOLA}

Bajo este epígrafe hemos reunido a aquellos que se encuentran en la Coruña y proceden en su mayor parte de América del Sur, aunque también nos encontraremos con algún que otro ejemplo de América Central, e incluso algunos que provienen de la Luisiana ${ }^{29}$. También hemos incluido a una persona que venía de Brasil.

Tabla VII

\begin{tabular}{lccc}
\hline PAISES & MUJERES & HOMBRES & TOTALES \\
\hline Perú & - & 2 & 2 \\
Venezuela & - & 1 & 1 \\
Uruguay & - & 1 & 1 \\
México & - & 2 & 2 \\
Colombia & - & 1 & 1 \\
Antillas & 1 & 8 & 9 \\
Luisiana & - & 2 & 2 \\
Brasil & - & 1 & 1 \\
\hline TOTALES & 1 & 18 & 19 \\
\hline
\end{tabular}

${ }^{27}$ E. FERREIRA PRIEGUE, Galicia en el comercio marítimo medieval; La Coruña, 1987; MEIJIDE PARDO, A., El comercio del bacalao en la Galicia del XVIII; La Coruña, 1980.

${ }^{28}$ A.M.C., sección Libros de Actas, caja $n^{\circ}$ 83, sesiones del 25-VIII-1800 al 28 VIII-1800.

${ }^{29}$ Que a comienzos del siglo XIX pasó a manos francesas, pero en la época durante la que nacieron estos dos individuos aún seguía siendo posesión española, y con la que se mantenían importantes relaciones comerciales.

"CUADERNOS DE ESTUDIOS GALLEGOS", Tomo XLVI, Fascículo 111, Santiago 1999. 
Lógicamente, la presencia de estos individuos en la ciudad de la Coruña está muy condicionada por la distancia. A esto hay que sumar las cada vez más que frecuentes escaramuzas que tienen lugar entre los navíos españoles e ingleses sobre todo, por lo que suponemos que las condiciones para navegar no debían de ser las más idóneas. Es probable que por este motivo la presencia de americanos en Coruña no sea muy importante.

El mayor número de personas lo ofrecen aquellas que provienen de lo que hemos denominado Las Antillas: Cuba, Puerto Rico, Jamaica, y alguna que otra pequeña isla de las Antillas. Como se puede apreciar son en su inmensa mayoría hombres -tan solo aparece una mujer, y es de La Habana- y de ellos un elevado número suponemos que serían marineros, pues en alguna ocasión así se indica, y en otra sólo se menciona que «... venía en un navío» $\mathrm{o}$ «... procedente de tal embarcación».

\section{ACTIVIDADES PROFESIONALES}

En un apartado anterior vimos como las posibilidades económicas de la Coruña en este momento podían ayudarnos a explicar la presencia de gentes foráneas en la ciudad. También observamos como la mayoría de la población era gallega, y en concreto de las comarcas próximas, decreciendo su número según nos alejábamos de Coruña. Si nos detenemos un poco en sus ocupaciones profesionales, veremos como la gran mayoría eran gente sin especializar.

Las mujeres, de un total de 47 en las que se recoge su profesión, declaran ser $24(51,06 \%)$ criadas o sirvientas. Podemos afirmar que casi todas se encuentran dentro de los 50 kilómetros antes mencionados ${ }^{30}$, salvo dos o tres casos de las provincias de Pontevedra y Lugo. En otros 17 ocasiones anota el párroco «su oficio pobre», y el resto son 2 pescadoras, 2 costureras, 1 lavandera y 1 vendedora. Por desgracia no son muchas las

${ }^{30}$ Algunos ejemplos pueden verse en: RAMA PATIÑO, $\mathrm{M}^{\mathrm{a}}$.L., «Una cala en la zona de inercia. El sector occidental de la antigua provincia de la Coruña (1700-1860)», pp 105 y ss.; VARELA PARDO, $\mathrm{M}^{\mathrm{a}}$.R., «La emigración de cuatro arciprestazgos coruñeses a través de fuentes diocesanas», pp. 87; SOBRADO CORREA, H., «Aproximación al fenómeno migratorio en la Galicia interior de Antiguo Régimen: la tierra de Castroverde, 1700-1850», en EIRAS ROEL, A. (Dir.) Aportaciones al estudio de la emigración gallega. Un enfoque comarcal, Santiago, 1992.

"CUADERNOS DE ESTUDIOS GALLEGOS", Tomo XLVI, Fascículo 111, Santiago 1999. 
menciones que tenemos, pero creemos que suficientes para hacernos una idea aproximada de los oficios que desempeñaban estas mujeres en la ciudad. A este oficio habría que sumarle otra dedicación tradicionalmente femenina, a la que ya se hacía referencia en el informe de la Junta de Gobierno del Hospital, como es la prostitución. Lógicamente una ciudad en crecimiento, con un comercio importante, un puerto con mucho tráfico, y en definitiva, una ciudad dinámica, con una población también bastante activa debía de ofrecer muchas posibilidades a estas mujeres. Y su presencia no debía de pasar desapercibida en las calles de la Coruña, a juzgar por el informe de la Junta del Hospital (...considerable número de mugeres públicas y poco fieles de cuio vicio no las contiene ni la umana ni la divina ....) ${ }^{31}$.

Ya por último, y como dato curioso, reseñar que en el año 1804 se produce un incremento considerable en el número de mujeres que llegan a la ciudad. No sabemos a que puede ser debido con exactitud, pero creemos que tendrá que estar relacionado con el hecho de que en ese mismo año empiece a trabajar de forma provisional -de hecho empezará de forma oficial en $1808^{32}$ - una industria que emplea fundamentalmente mano de obra femenina, como es la Fábrica de tabacos lo que podría ayudar a explicar ese incremento en la llegada de mujeres ${ }^{33}$ a la ciudad.

En lo que se refiere a los hombres, estos presentan una mayor diversidad de oficios, pero siguen siendo en su mayoría sin especializar. Hemos obtenido un total de 98 referencias a oficios masculinos ${ }^{34}$, y se reparten como sigue:

${ }^{31}$ A.M.Coruña, Junta Municipal de Beneficencia, Caja $n^{\circ} 79$.

${ }^{32} \mathrm{De}$ acuerdo con la información ofrecida por P. Madoz «comenzaría a elaborar en 1808 (...) elevandose su producion a más de 35.000 libras de cigarros comunes» y su personal alcanzaba en 1808 la cifra de «100 cigarreras». MADOZ, P.: Diccionario Geográfico-Estadístico-Histórico de España y sus posesiones de Ultramar. Madrid, 1845 (Edición Facsimil, Madrid, 1986).

${ }^{33}$ En el año de 1804 se registran en el Hospital un total de 90 mujeres foráneas y 25 naturales de la Coruña, cuando la media es aproximadamente en 1796-1800 de 40 mujeres foráneas y de 15 autóctonas, y durante $1801-1805$ es de 60 forasteras y de 20 coruñesas.

${ }^{34}$ Descontando las 41 menciones de soldados que tenemos, que suponemos no estarían aquí por voluntad propia (sobre todo los foráneos). De hecho tampoco los hemos incluido ya que las menciones que se hacen a ellos es por ser el marido de numerosas enfermas «.... su marido cabo en el batallon de Ynbalidos»; «... su esposo es sargento del Regimiento de America» (de 36 en total), y no por estar ellos ingresados en el hospital (por lo que tampoco podíamos saber su naturaleza).

"CUADERNOS DE ESTUDIOS GALLEGOS", Tomo XLVI, Fascículo 111, Santiago 1999. 


\begin{tabular}{|c|c|c|}
\hline Marineros ....... 18 & Frailes ...................... 4 & Fondero …........................ \\
\hline Sirvientes ....... 12 & Bodegueros ... & Enfermeros ... \\
\hline Carpinteros ..... 11 & Jornaleros ............. 3 & Arriero ......... \\
\hline Peones ................ 6 & Labradores ............. 3 & Barbero ............. \\
\hline Sastres.... & Escribanos. & Receptor Trib. \\
\hline Canteros ............... 4 & Peluqueros ............. 2 & Esquilador ... \\
\hline Zapateros .......... 4 & Alguaciles ............. 2 & Albañil .................. 1 \\
\hline \multirow[t]{2}{*}{ Pobres ................ 4} & Ciru & Panadero ................. 1 \\
\hline & Sombrereros & Molinero ... \\
\hline
\end{tabular}

A la vista de los datos no abundaban precisamente los oficios en los que se requiera una alta cualificación. En relación con esto hay que comentar, que aunque no sucede siempre, pero si con cierta frecuencia, parece haber alguna relación entre la distancia recorrida y el oficio que realizan en la ciudad. Los que vendrían de zonas más alejadas -descontando a los militares y a los marineros- serían los cirujanos, los escribanos, el receptor de cuentas del Tribunal, los dos peluqueros (madrileños), uno de los sastres (madrileño), un operario de la fábrica de sombreros y el zapatero (estos dos últimos serían portugueses). El resto de los mencionados serían gallegos, y en su mayoría de las proximidades de la ciudad, salvo tres canteros (naturales de San Martín de «Alaxe» -Moraña-, de Santa Maria de Cequiril -Cuntis- y de San Lorenzo de Almofrei -Cotobadetodos de la Provincia de Pontevedra) ${ }^{35}$, un carpintero (de San Adrian de Calvos en Fornelos de Montes), y el arrierro (natural de san Miguel de Candeda -A Veiga- Orense).

\footnotetext{
${ }^{35}$ Lo que no resulta extraño, según han puesto de manifiesto diversos trabajos, como puede verse en GONZÁLEZ LOPO, D.: «Una aproximación a la emigracion de la Galicia Occidental entre mediados del siglo XVII y el primer tercio del XX, a través de las fuentes de protocolos y archivos parroquiales»; en Revista da Comisión Galega do Quinto Centenario, $\mathrm{n}^{\circ}$ 6, Santiago, 1989, págs. 137-169; FERNÁNDEZ CORTIZO, C.: «Ganando la vida con el oficio de cantero: explotación campesina y emigración estacional en la Galicia occidental del siglo XVIII»; en Actas de la I Conferencia Europea de la Comisión Internacional de Demografia Histórica. Santiago, 1993. págs. 337-354.
}

"CUADERNOS DE ESTUDIOS GALLEGOS", Tomo XLVI, Fascículo 111, Santiago 1999. 
Pero aunque solo aparezcan las actividades laborales en tan escaso número de ocasiones, suponemos que un número superior al de los varones antes reseñados estarían trabajando en las obras de remodelación de La Coruña, pues en más de una ocasión se dice «... accidentado en las obras de la Palloza; .... trabajando en las obras del puerto» y es durante esta época cuando se remodela el puerto y se incorporan nuevas barrios a lo que antes era el núcleo de la ciudad. Por supuesto, a todos estos oficios habría que sumarles un numero importante de soldados, que también pasarían por el hospital durante estos años ${ }^{36}$.

\section{ALGUNAS CONSIDERACIONES SOBRE LA SANIDAD}

Aunque no era uno de los objetivos iniciales de este trabajo analizar el funcionamiento del Hospital de la Caridad, una vez que contamos con datos que podrían ayudar a ver algunos aspectos concretos, nos hemos decidido a comentarlos de una manera muy breve, y desde luego sin entrar en muchos detalles, ya que muchos de ellos se escapan a nuestros conocimientos. Por supuesto no son más que datos aproximados, y que solamente servirán para hacernos una idea de la realidad de la vida cotidiana del Hospital. Y tratados de forma más organizada y sistemática podrían utilizarse, sacándole mayor partido del que nosotros le hemos sacado.

Pasando ya a analizar las causas por las que entran en el hospital las personas registradas, una gran cantidad de ellas lo hacen por causa de lo que hemos denominado «fiebres» ${ }^{37}$.

En la Tabla VIII, observamos como prácticamente el número de mujeres que entran aquejadas de esta enfermedad es igual al de los hombres. Nos encontramos en segundo lugar, en el caso de las mujeres con algo tan

\footnotetext{
${ }^{36}$ Como se pone de manifiesto en los libros de reuniones del ayuntamiento, a causa de los problemas que hay con el alojamiento de los soldados, y se ordena llevar a los soldados sarnosos al hospital para evitar el roce con los soldados sanos. A.M.C., Libros de Actas, Caja n 83, sesión del 21-V-1800, f. 58-59.

${ }^{37}$ En donde englobaríamos las menciones de calenturas, fiebres, tercianas, cuartanas, ...
}

"CUADERNOS DE ESTUDIOS GALLEGOS", Tomo XLVI, Fascículo 111, Santiago 1999. 
Tabla VIII. Distribución de las enfermedades más frecuentes

\begin{tabular}{ccccr}
\hline$\%$ & MUJERES & ENFERMEDAD & HOMBRES & $\%$ \\
\hline 27,47 & 86 & Calenturas & 70 & 28,45 \\
13,09 & 41 & Dolores & 13 & 5,28 \\
8,94 & 28 & Hidropesia & 20 & 8,13 \\
8,62 & 27 & Erisipela & 26 & 10,56 \\
7,34 & 23 & Accidentes & 21 & 8,53 \\
7,34 & 23 & Sarna & 15 & 6,09 \\
5,75 & 18 & Mal de pecho & 21 & 8,53 \\
4,47 & 14 & Tumores & 13 & 5,28 \\
2,87 & 9 & Flujo de sangre & 6 & 2,43 \\
1,60 & 5 & Fracturas & - & - \\
1,27 & 4 & Gangrenas & - & - \\
1,60 & 5 & Sarampión,viruela y tabardillo & 7 & 2,84 \\
6,38 & 20 & Otros & 34 & 13,82 \\
3,19 & 10 & Partos & - & - \\
\hline 100 & 313 & TOTALES & 246 & 100 \\
\hline
\end{tabular}

genérico como puedan ser los «dolores». Bajo esta denominación hemos incluido dolores varios «de cabeza, de garganta, de vientre, de estómago, de brazos, ...». A continuación, y a muy escasa distancia una de otra, aparecen la hidropesia y la erisipela, afectando casi por igual a hombres y a mujeres. Por último y casi a modo anecdótico, comentar que de las 10 mujeres atendidas de parto 8 estaban solteras, lo que en parte parecería confirmar lo escrito unas líneas atrás referente al ejercicio de la prostitución por parte de las féminas llegadas a la ciudad.

Lógicamente no entraremos a comentar las enfermedades, pues entre otras cosas, están anotadas por el párroco, y como podemos ver sus definiciones son un tanto imprecisas y vagas. Además la clasificación que nosotros hemos hecho, posiblemente no se adapte mucho a la realidad de la época, pero es ciertamente difícil homogeneizar ante frases tan escuetas como «... entro baldada de un lado»; « ... hinchada»; «tenía dolores ...»; «... con un punto»; «... mal de ojos...». Lo que si salta a la vista es que unas óptimas condiciones sanitarias e higiénicas no estaban precisamente a la orden del día, a juzgar por las menciones de erisipela, sarna, tabardillo y sobre todo de «miseria», que no hemos contabilizado por no saber muy bien en que grupo englobarla, pero que, ciertamente, encajaría

"CUADERNOS DE ESTUDIOS GALLEGOS", Tomo XLVI, Fascículo 111, Santiago 1999. 
con la situación de deterioro a la que aludíamos con anterioridad y que llevaría a gran cantidad de pobres a la ciudad herculina.

Podíamos intentar también calcular los días de estancia en el Hospital y a continuación veremos los resultados que hemos obtenido. En la tabla IX, se han calculado el tiempo de estancia en el hospital de las mujeres y de los varones. En la columna I se especifica el número de personas muertas en cada tramo, y en la número II el porcentaje que supone sobre el número total de gente que permaneció ese tiempo en el hospital.

Tabla IX

\begin{tabular}{rrrrcrrrr}
\hline \multicolumn{2}{c}{ MUJERES } & \multicolumn{1}{c}{ I } & \multicolumn{1}{c}{ II } & D. DE ESTANCIA & HOMBRES & \multicolumn{1}{c}{ I } & \multicolumn{1}{c}{ II } \\
\hline 474 & $62,94 \%$ & 58 & $12,23 \%$ & $1-30$ & 296 & $62,71 \%$ & 61 & $20,60 \%$ \\
179 & $23,77 \%$ & 17 & $9,50 \%$ & $31-60$ & 122 & $25,84 \%$ & 14 & $11,47 \%$ \\
57 & $7,57 \%$ & 10 & $17,54 \%$ & $61-90$ & 27 & $5,72 \%$ & 3 & $11,11 \%$ \\
26 & $3,45 \%$ & 3 & $11,53 \%$ & $91-180$ & 17 & $3,60 \%$ & 4 & $23,53 \%$ \\
13 & $1,72 \%$ & 7 & $53,84 \%$ & $181-270$ & 5 & $1,05 \%$ & 2 & $40 \%$ \\
1 & $0,13 \%$ & 1 & $100 \%$ & $271-365$ & 2 & $0,42 \%$ & 2 & $100 \%$ \\
3 & $0,39 \%$ & 2 & $66,66 \%$ & +365 & 3 & $0,63 \%$ & 2 & $66,66 \%$ \\
\hline 753 & $100 \%$ & 128 & & TOTALES & 472 & & 88 & \\
\hline
\end{tabular}

\section{CONCLUSIONES}

A modo de resumen podemos decir que en este período, 1796-1805, la ciudad de la Coruña que está experimentando una fase de expansión, recibe población que procede, en su inmensa mayoría de las comarcas limítrofes con la urbe. Son gentes que provienen del campo, y ante la fuerte demanda de mano de obra que existe en este momento en la ciudad, se acercan a ella gentes de las poblaciones vecinas. Gentes, en su mayoría, con una escasa especialización profesional y que acaban dedicándose a las labores más variadas una vez avecindados en la ciudad, que serán los responsables del importante crecimiento urbano que entonces tiene lugar ${ }^{38}$.

${ }^{38}$ BARREIRO MALLÓN, B.: La ciudad de la Coruña según las Respuestas Generales del Catastro de Ensenada. Madrid, 1990, pág. 37.

"CUADERNOS DE ESTUDIOS GALLEGOS", Tomo XLVI, Fascículo 111, Santiago 1999. 
Hay una diferencia en número considerable entre hombres y mujeres, y la situación también se presenta desigual en cuanto a su estado civil. Hay una mayor proporción de féminas solteras entre las foráneas, y en los varones está más igualado su número en cuanto a solteros y casados.

El resto de España está representado fundamentalmente por gentes de la Cornisa Cantábrica, en particular, y en general de la zona norte. La población del resto de la península va disminuyendo su presencia conforme aumenta la distancia y su presencia en la ciudad parece estar determinada por las actividades económicas y comerciales que en ella desempeñan.

\section{BIBLIOGRAFÍA}

ALONSO ÁlVAREZ, L., Comercio colonial y crisis del Antiguo Régimen en Galicia. Sada, 1986.

BARREIRO MALLÓN, B., La ciudad de La Coruña según las Respuestas Generales del Catrastro de Ensenada. Madrid, 1990.

CARASA SOTO, P., Pauperismo y revolución`burguesa (Burgos 17501900). Valladolid, 1987.

CHAUNU, P., La mort à Paris. XVI ${ }^{e}, X V I I^{e}, X V I I I^{e}$, siècles. Paris, 1978.

EIRAS ROEL, A., Estudios sobre agricultura y población en la España Moderna. Santiago, 1986.

- Aportaciones al estudio de la emigración gallega. Un enfoque comarcal. Santiago, 1992.

FAUVE-CHAMOUX, A., «Female mobility and urban population in preindustrial France (1500-1900)», en Actas de la I Conferencia Europea de la Comisión Internacionalde Demografía Histórica. Santiago, 1993, págs. 43-72.

FERREIRA PRIEGUE, E. Galicia en el comercio marítimo medieval. La Coruña, 1987.

"CUADERNOS DE ESTUDIOS GALLEGOS", Tomo XLVI, Fascículo 111, Santiago 1999. 
FERNÁNDEZ CORTIZO, C., «Ganando la vida con el oficio de cantero: explotación campesina y emigración estacional en la Galicia occidental del siglo XVIII», en Actas de la I Conferencia Europea... págs. 337-354.

GONZÁLEZ LOPO, D.L., «Una aproximación a la emigración de la Galicia Occidental entre mediados del siglo XVII y el primer tercio del $\mathrm{XX}$, a través de las fuentes de protocolos y archivos parroquiales», en Revista da Comisión Galega do Quinto Centenario, $\mathrm{n}^{\circ}$ 6, Santiago, 1989, págs. 137-189.

LUCAS LABRADA, J., Descripción económica del Reino de Galicia. Vigo, 1971.

MADOZ, P., Diccionario Geográfico-Estadístico-Histórico de España y sus posesiones de Ultramar. Madrid, 1845 (Edición Facsimil, Madrid, 1986).

MARTÍNEZ RODRÍGUEZ, E., BURGO LÓPEZ, C., GONZÁLEZLOPO, D., «Inmigración urbana en la Galicia del A.R.: Santiago, Tuy y Ferrol a finales del siglo XVIII», en Actas de la I Conferencia Europea de la Comisión Internacional de Demografía Histórica. Santiago, 1993, T. II, págs. 389-402.

MEIJIDE PARDO, A., El comercio de bacalao en la Galicia del XVIII. La Coruña, 1980.

MAZA ZORRILLA, E., Valladolid: sus pobres y la respuesta institucional (1750-1900). Valladolid, 1985.

PALOMARES IBÁÑEZ, J.Mª., «El arzobispo Rajoy y los orígenes del Hospicio de Pobres de Santiago»; en Cospostellanum (1977), págs. 235-259.

RAMA PATIÑO, $\mathrm{M}^{\mathrm{a}} \mathrm{L}$., «Una cala en la zona de inercia. El sector occidental de la antigua provincia de La Coruña (1700-1860)», en EIRAS ROEL, A., (dir), Aportaciones al estudio de la emigración...; pág. 105112.

"CUADERNOS DE ESTUDIOS GALLEGOS", Tomo XLVI, Fascículo 111, Santiago 1999. 
SOBRADO CORREA, H., «Aproximación al fenómeno migratorio en la Galicia interior de Antiguo Régimen: la tierra de Castroverde, 17001850», en EIRAS ROEL, A. (dir), Aportaciones al estudio de la...; págs. 139-143.

VARELA PARDO, $\mathrm{M}^{\mathrm{a}} \mathrm{R}$. , «La emigración de cuatro arciprestazgos coruñeses a través de fuentes diocesanas», en EIRAS ROEL, A. (dir), Aportaciones al estudio de la emigración...; págs. 71-76.

\section{FUENTES MANUSCRITAS}

Archivo Municipal de La Coruña:

- Sección Junta Municipal de Beneficencia, cajas 79 y 1566.

- Sección Libros de Acuerdos Municipales, años 1796-1805. 